\title{
Estimating the Output Gap of Pakistan on Quarterly Frequency Using Structural Methods
}

\author{
Mian Abdullah Tahir ${ }^{1}$ \\ ${ }^{1}$ School of Economics, Jilin University, Changchun, China \\ Correspondence: Mian Abdullah Tahir, School of Management, School of Economics, Jilin University, \\ Changchun, China. Tel: 86-431-8516-6030. E-mail: mian.abdullah@gmail.com
}

Received: February 21, 2014

Accepted: March 19, 2014

Online Published: April 25, 2014

doi:10.5539/ijef.v6n5p233

URL: http://dx.doi.org/10.5539/ijef.v6n5p233

\begin{abstract}
Estimates of latent macroeconomic variables like Output Gap and Potential Output have Monetary and Fiscal policy significance at high data frequency. Unlike previous, this study aims to circumvent the issue of dearth of quarterly national Income accounts for Pakistan by estimating a robust proxy for real total output based on Large Scale Manufacturing Index (LSM). This paper implements three commonly employed methods for estimating the output gap, these include; State-Space model, Wavelet filter and Structural VAR model. I conclude that in line with the macroeconomic aggregates; demand pressures in Pakistan have subsided since FY2009Q3 in addition negative output gap since 2011Q3 is due to slowdown in real economy, i.e., the aggregate supply. Lastly, I forecast that the current trend of low aggregate demand is expected to last until FY2015Q4.
\end{abstract}

Keywords: state-space models, potential output, output gap

\section{Introduction}

Potential output is an estimate of maximum output attainable by the economy within the existing stock of capital and labor without adding pressures on inflationary tendencies (Conway \& Hunt, 1997). Estimates of output gap (i.e., deviations of Actual output from potential output) can function as useful indicator for macroeconomic policy implementation and assessment. Estimating potential output and the output gap are also useful as fiscal and monetary policies need to be aligned with the information whether the economy is above or below its sustainable long run capacity. Recent literature suggests that potential output is that level of output; where there are no excess inflationary pressures existing in the economy. In case when the output gap is positive i.e., Actual Output $>$ Potential Output, implies that there is excess demand in the economy, and in case where output gap exhibits a negative value (i.e., Actual Output $<$ Potential Output) it implies the existence of excess supply. In essence of Blanchard and Quah (1989) shocks to total output can be categorized as either A: Short run fluctuations (transitory) or B: Permanent (persistent) shocks, to the production capacity of the economy. From macroeconomic policy perspective it is imperative to know whether the change in output is caused by demand shocks or supply shocks or whether the economy is capable of more supply.

Economy of Pakistan since 2004 recent years has experienced persistent double digit inflation, rising unemployment and slowdown in real GDP. Only recently since Q1-FY2014Q1 economy of Pakistan has depicted signs of recovery. In this scenario it is important to estimate and analyze the short run trend of total output of Pakistan.

I aim to estimate the potential out and vis-a-viz the output gap using three methods, these are wavelet filter method, State-Space Method and Structural VAR. Resultant output gap for the period 1991Q2-2014Q1 indicate that the three methods have general coherence in estimates. I show that Pakistan economy has experienced three complete phases of positive and negative output gaps, in addition recent estimates suggest that Pakistan economy is currently experiencing recovery from extended bout of latest negative output gap. Extending our analysis I conclude using a simple ARIMA model that the recent negative output gap phase is estimated to last until FY2015Q4.

The paper is structured as follows section 2 presents relevant literature review, methodologies for estimating output gap are discussed in section 3 , section 4 contains discussion on estimates and section 5 concludes. 


\section{Literature Review}

Validity of output gap estimates in the literature build generally upon tree factors; their inflation forecasting power, Economic viability of estimates and theoretical foundation of these methods. Chagny and Lemoine (2004) note however that no definite consensus exists in favor of any one method of output gap estimation. Dennis et al (2006) declares that no single method can be unequivocally stated as the best. Billmeier (2004a) concludes in disfavor of any particular methodology where poor out-of-sample inflation forecasting is the cause of this conclusion, however in another study Billmeier (2004b) concludes univariate filter to contain better forecasting power for the case of Finland.

Development of Multivariate HP filter at the Bank of Canada and the Bank of New Zealand in the late 1990s led to conclusion of superiority of this method over simple univariate methods on two points, One, Multivariate filters as in Dupasquier et al. (1997), Conway and Hunt (1997), Coe and McDermott (1996) and Gibbs (1995) contain economic foundation for the estimation of output gap in the form of inclusion of Phillips' curve identity, secondly, These methods are shown to have good out of sample forecasting capability for inflation. Recently Benes et al. (2004) employ a modified Multivariate filter by incorporating capacity utilization, unemployment, inflation and the Real GDP to extract the output gap, they conclude robustness of these estimates by conducting this study on various countries.

Output Gap estimation a-la Blanchard and Qua (1989) led to economic theory based estimation of output gap, Structural representation of VAR is utilized by imposing long run restrictions using unemployment, inflation and total real output to estimate the potential output. Scott A (2000) and Gounder and Morling (2000) draw favorable conclusion for SVAR method in estimating output gap. Other similar studies include Billmeier (2004a), Cerra and Saxena (2000), Chantanahom et al. (2002), Dupasquier et al. (1997), Funke (1997), to name a few.

Proponents of State-Space methodology (Unobserved Components method) claim inherently viable estimation of output gap consistent simultaneous with nature of the latent variable and the estimation method. Clark (1987) and Harvey and Jaeger (1993) estimate output gap using this methodology and conclude in its favor. Recently Cayen and Van Norden (2004), Bjørnland et al. (2006), Aroujo et al. (2004), Adnan and Safdar (2008) conclude favorably for Unobserved components model in estimating output gap. It is worthwhile to note here that Unobserved components method and Multivariate HP filter method share some similar grounds as the output gap In both methods is estimated by sequentially evaluating the likelihood function using Kalman filter method (see Benes et al., 2004).

Most studies conclude that variation in estimates of output gap exist within methodologies. Coe and McDermott (1996) conclude the end-of-sample inadequate estimates of output gap for univariate methods; whereas Kalman filter based methods yield better results. Recently Bayesian methods for output gap estimation have grown in popularity (see Berger \& Kemp, 2011), also in vogue recently are estimation based on theoretically sound foundations i.e., in Dynamic Stochastic General Equilibrium models; see Michel Juillard et al. (2006), Leist and Neusser (2010), Hirose and Naganuma (2009).

\section{Method}

Before moving on, data sets used in estimation is taken from SBP annual reports, SBP Statistical Bulletin, Planning Commission of Pakistan's Economic Survey of Pakistan (various editions). Elaborating further, a proxy series for RGDP is obtained by utilizing Large Scale Manufacturing Index (LSM) as quarterly estimates of RGDP for Pakistan are not available (see Annexure 1). Real GDP is in billions of Pakistan Rupees (PKR) adjusted for CPI inflation; base year for Real GDP is FY2006. Consumer Price Index (CPI) is taken as a gauge of Inflation in Pakistan; annual Consumer Price Index is taken on base year FY2006. Data on RGDP, CPI and Unemployment are in the range FY1991Q3-FY2014Q1.

In light of literature review I employ here three different methods for estimating the potential output and the output gap, I discuss them as under.

\subsection{State Space Method}

Theoretically Potential output and the output gap are latent variables that can be modeled to be extracted from the (observed) Real GDP as the trend and cyclical components of the Real GDP time series respectively. Kalman filter offers are natural and inherently suitable means to do that as Kalman filter can be seen as a means to solve for the Linear Quadratic Problem of estimating the instantaneous 'State' of a linear dynamic system perturbed by white noise, the resulting estimator is optimal statistically with respect to the quadratic function of the estimation error. In short the unobserved states can be optimally estimated through the Kalman filtering algorithm using the observed variables. Elaborating further, Kalman filter can be used to estimate unobserved 
variables given that they appear as explanatory variables in a State-Space model; where a State-Space representation is one that constitutes a "measurement" equation. This equation states 'observed variables' as a function of unobserved variable(s) (also called State variable(s)) and some 'transition' equations describing the path of the unobserved variable over time.

Kalman filter can be exemplified as;

Measurement Equation:

$$
Y_{t}=\alpha X_{t}+\beta Z_{t}+\varepsilon_{t} \text { where } \varepsilon_{t} \sim N(0, \delta)
$$

Where;

$Y_{t}$ : is a vector of observed variables;

$X_{t}$ : is a vector of unobserved variables;

$Z_{t}$ : is a vector of exogenous variables.

Transition Equation:

$$
X_{t}=\gamma X_{t-1}+\epsilon_{t} \text { where } \epsilon_{t} \sim N(0, \theta)
$$

And, $\gamma$ is a vector of parameters.

The above representation may be estimated by means of a Kalman filter, a recursive procedure which, combined with a maximum likelihood estimation method, gives optimal estimates of unobserved components. State-Space models utilizing Kalman filter method to estimate Output Gap has been extensively utilized in recent years. Notable examples of Output Gap estimation are discussed in detail in Boone (2000). Also, Harvery (1985) utilizes an interesting approach by which he has employed Actual Output and Unemployment (observed variables) to estimate the potential output (unobserved variable), thus arriving at the Output Gap. This approach is consistent with the standard economics definition of the Output Gap. The methodology adopted in this manuscript is consistent with that in Harvey (1985), Watson (1986) and Vineet (2004). I incorporate a typical Phillips' curve within the Unobserved components model in order to extract the output gap. Output is modeled to be decomposed in to a trend and cycle component, where trend is modeled to be random walk with drift and cycle component is assumed as an autoregressive series. In essence of a standard Unobserved components model I present here the State and Space equations as;

$$
\text { Signal Equation 1: } Y_{t}=Y_{t}^{\text {trend }}-Y_{t}^{\text {cycle }}
$$

Signal Equation 2: $\pi_{t}=\pi_{t}^{*}$

State Equation 1: $Y_{t}^{\text {trend }}=Y_{t-1}^{\text {trend }}+\mu_{t-1}+\epsilon_{t}$ where; $\epsilon_{t} i i d \sim N\left(0, \delta_{\epsilon}^{2}\right)$

State Equation 2: $\mu_{t}=\mu_{t-1}+\psi_{t}$ where; $\psi_{t}$ iid $\sim N\left(0, \delta_{\psi}^{2}\right)$

State Equation 3: $Y_{t}^{\text {cycle }}=\tau_{1} Y_{t-1}^{\text {cycle }}+\omega_{t}$ where; $\omega_{t}$ iid $\sim N\left(0, \delta_{\omega}^{2}\right)$

State Equation 4: $\pi_{t}=\tau_{2} \pi_{t-1}+\tau_{2} \pi_{t}^{*}+\tau_{3} Y_{t-1}^{c y c l e}+\varphi_{t}$ where; $\varphi_{t}$ iid $\sim N\left(0, \delta_{\varphi}^{2}\right)$

Where;

$Y_{t}:$ Log of Real GDP.

$Y_{t}^{\text {trend }}$ : Trend component of Real GDP.

$Y_{t}^{\text {cycle }}$ : Cyclical Component of Real GDP (assumed to be AR(1) process).

$\pi_{t}$ : CPI Inflation.

$\pi_{t}^{*}$ : Target Inflation.

$\mu_{t}$ : The drift component of trend RGDP is assumed to be an arbitrary constant.

Parameters of the above equations are estimated by sequentially evaluating the Likelihood function using the Kalman filtering methodology (see Grewal \& Andrews, 2001 for theoretical underpinning of Kalman filtering). Figure 1 depicts Potential Output estimates in comparison with RGDP. 


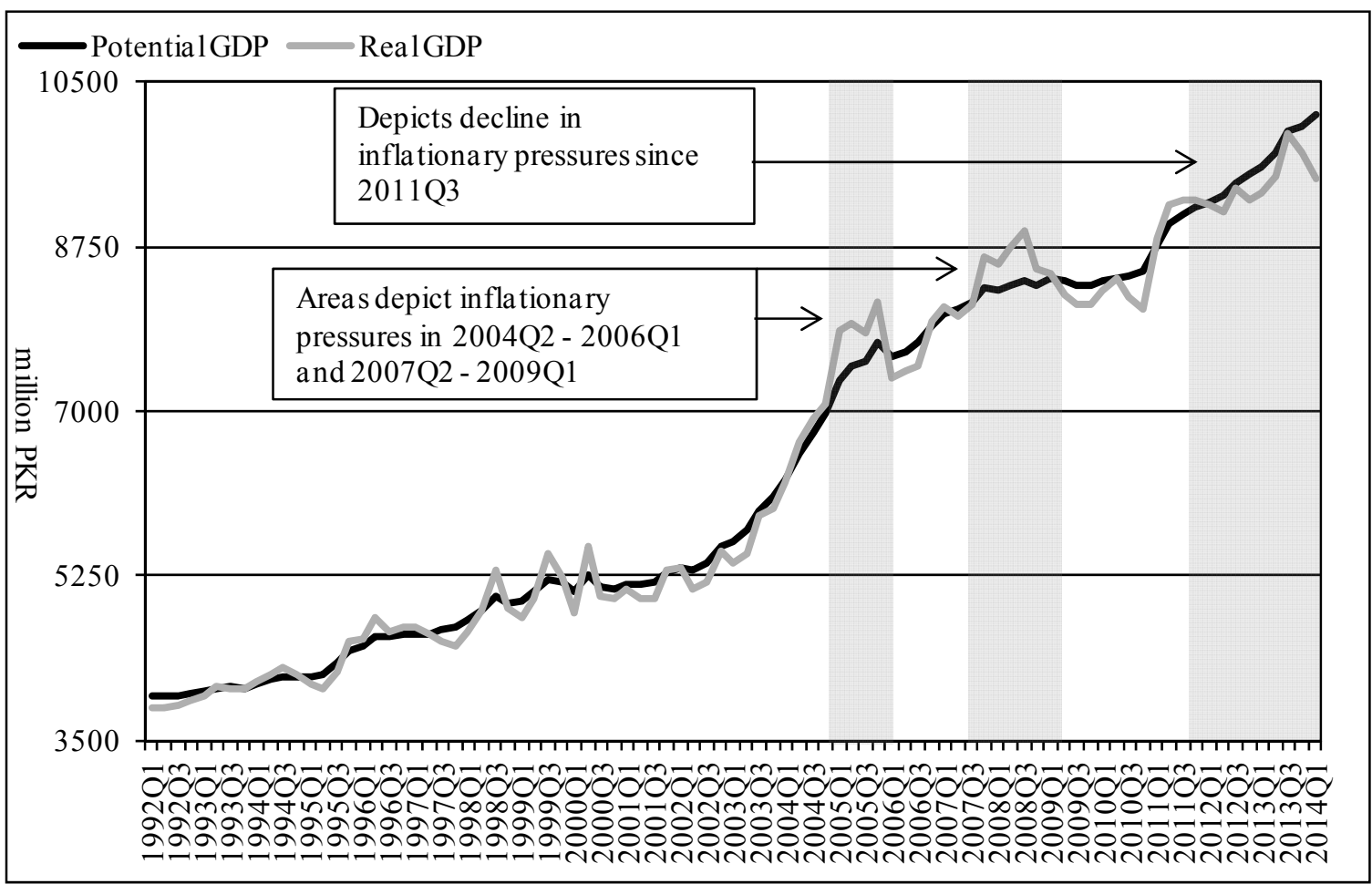

Figure 1. Real GDP and potential GDP on quarterly frequency for Pakistan, state-space method

\subsection{Structural Vector Autoregression (SVAR) Method}

In line with Bjørnland et al. (2006), I estimate a three variable SVAR; I implement long run restrictions consistent with Blanchard and Quah (1989). Where, Blanchard and Quah (1989) use long run restrictions on a two variable model in VAR methodology by subjecting it to structural constraints in order to draw long run (permanent) shocks and short run (transitory) shocks to the system. As at high data frequency like in quarterly Real GDP short run is characterized by the assumption of constant stock of factors of production, constant habits and constant productivity, any transitory or short run shocks can be interpreted as emanating from aggregate demand side of the economy. Whereas in the long run stock of factors of production, habits, expectations, productivity and technology are all assumed to be dynamic, therefore persistent shocks can be interpreted as emanating from the aggregate supply or real economy.

I specify 3 variables VAR ordered as Unemployment, Real GDP and CPI Inflation along with the structural restrictions as below;

Or;

$$
\begin{aligned}
\Delta u_{t} & =\sum_{K=0}^{\infty} A_{11}(K) \varepsilon 1_{t-k}+\sum_{K=0}^{\infty} A_{12}(K)_{\varepsilon} 2_{t-k}+\sum_{K=0}^{\infty} A_{13}(K) \varepsilon 3_{t-k}+\psi_{u} \\
\Delta y_{t} & =\sum_{K=0}^{\infty} A_{21}(K) \varepsilon 1_{t-k}+\sum_{K=0}^{\infty} A_{22}(K) \varepsilon 2_{t-k}+\sum_{K=0}^{\infty} A_{23}(K) \varepsilon 3_{t-k}+\psi_{y} \\
\pi_{t} & =\sum_{K=0}^{\infty} A_{31}(K) \varepsilon 1_{t-k}+\sum_{K=0}^{\infty} A_{32}(K) \varepsilon 2_{t-k}+\sum_{K=0}^{\infty} A_{33}(K) \varepsilon 3_{t-k}+\psi_{\pi}
\end{aligned}
$$

$$
\left[\begin{array}{c}
\Delta u \\
\Delta y \\
\pi
\end{array}\right]_{t}=\left[\begin{array}{lll}
A_{11}(L) & A_{12}(L) & A_{13}(L) \\
A_{21}(L) & A_{22}(L) & A_{23}(L) \\
A_{31}(L) & A_{32}(L) & A_{33}(L)
\end{array}\right]\left[\begin{array}{c}
\varepsilon 1 \\
\varepsilon 2 \\
\varepsilon 3
\end{array}\right]+\left[\begin{array}{c}
\psi_{u} \\
\psi_{y} \\
\psi_{\pi}
\end{array}\right]_{t}
$$

Where, $\left[\begin{array}{llll}\psi_{u} & \psi_{y} & \psi_{\pi}\end{array}\right]$ is vector of deterministic trend, $A_{i i}(L)$ is notification for lag operator which is determined using; $E\left(\varepsilon_{t} \varepsilon_{t}^{\prime}\right)=I$, as the shocks are not observable, I estimate VAR of the form;

$$
\left[\begin{array}{c}
\Delta u \\
\Delta y \\
\pi
\end{array}\right]_{t}=\left[\begin{array}{lll}
H_{11}(L) & H_{12}(L) & H_{13}(L) \\
H_{21}(L) & H_{22}(L) & H_{23}(L) \\
H_{31}(L) & H_{32}(L) & H_{33}(L)
\end{array}\right]\left[\begin{array}{c}
\Delta u \\
\Delta y \\
\pi
\end{array}\right]_{t}+\left[\begin{array}{l}
\psi_{u} \\
\psi_{y} \\
\psi_{\pi}
\end{array}\right]_{t}+\left[\begin{array}{c}
\mu_{u} \\
\mu_{y} \\
\mu_{\pi}
\end{array}\right]_{t}
$$

It can be shown than the VAR residuals can be written as; 


$$
\left[\begin{array}{l}
\mu_{u} \\
\mu_{y} \\
\mu_{\pi}
\end{array}\right]_{t}=\left[\begin{array}{l}
\psi_{u} \\
\psi_{y} \\
\psi_{\pi}
\end{array}\right]_{t}+\left[\begin{array}{lll}
A_{11}(0) & A_{12}(0) & A_{13}(0) \\
A_{21}(0) & A_{22}(0) & A_{23}(0) \\
A_{31}(0) & A_{32}(0) & A_{33}(0)
\end{array}\right]\left[\begin{array}{c}
\varepsilon 1 \\
\varepsilon 2 \\
\varepsilon 3
\end{array}\right]
$$

Where, once identified $A(0)$ describes contemporaneous effects of structural innovations, while $\left[\begin{array}{llll}\varepsilon 1 & \varepsilon 2 & \varepsilon 3\end{array}\right]^{\prime}$ is defined as; $\varepsilon 1$ is permanent shock (Aggregate Supply shock), $\varepsilon 2$ Real Demand shock (Aggregate Demand shock), $\varepsilon 3$ is nominal demand shock. Here I impose long run restriction off the form $H_{11}(L)=H_{22}(L)=$ $H_{33}(L)=H_{21}(L)=H_{31}(L)=H_{32}(L)=0$, i.e., I impose a lower triangular matrix long run restriction.

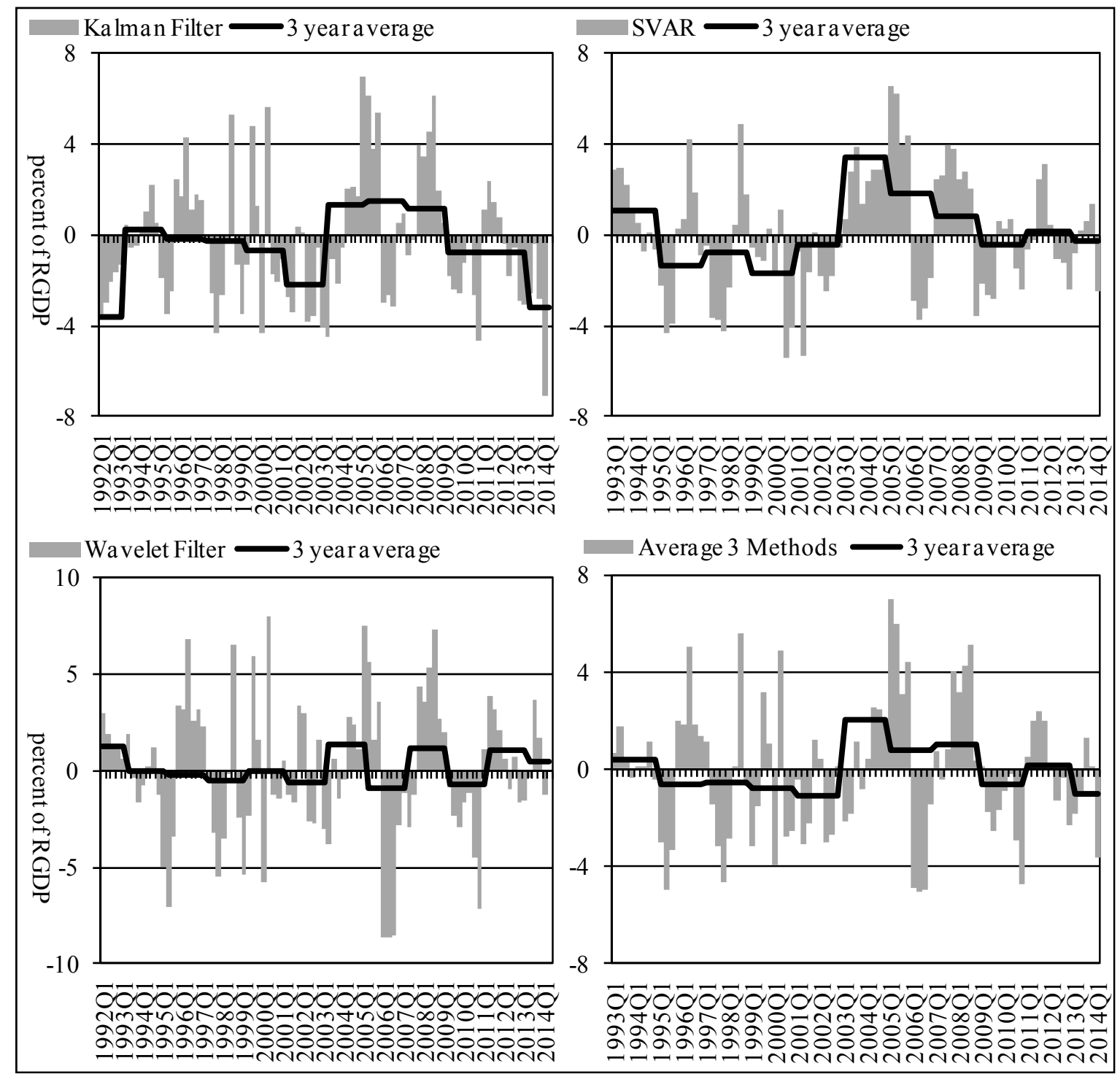

Figure 2. Estimates of output gap of Pakistan on quarterly frequency using 3 methods

Thus a $A_{i i}(L)$ can computed as Cholesky decomposition of the Covariance matrix of the variables, which in turn can be used to identify $A(0)$, this yield a theory consistent interpretation of shocks as being divided into a transitory component and another permanent component. Estimated output gap using the above methodology can be seen in Figure 2 below.

\subsection{Wavelet Filter Method}

Wavelet filtering is an excellent tool for analyzing properties of time series. In essence of Percival and Walden (2000) a typical Wavelet filter can be programmed to extract the long and short run trends in the time series as;

$$
y(t)=y_{\text {trend }}(t)+\sum_{j=0}^{2} y_{j}(t)
$$


Where $y(t)$ denotes real output, $y_{\text {trend }}(t)$ denotes trend component defined as cycles with periodicity greater than 16 quarters, and $y_{j}(t)$ denotes cyclical components with periodicity as; $y_{0}(t)$ depicts high frequency noise (i.e., cyclical periodicity between $0-4$ quarters), $y_{1}(t)$ show cyclical periodicity between $4-8$ quarters and lastly, $y_{2}(t)$ illustrate cyclical periodicity between $8-16$ quarters.

Cyclical components extracted with wavelet filter of the above representation closely represents the cyclical component extracted using an approximate Band pass filter see Baxter and King (1999). Wavelet filter has the advantage over approximate Band pass filter by extracting cyclical component over the entire range of the sample. I implement the wavelet filter consistent with the methodology and implementation in Motohiro (2008) (Note 1), the $J$-level wavelet decomposition of a continuous time series can be depicted as;

$$
y(t)=\sum_{k}{\tilde{a_{0 k}}}_{0 k}(t)+\sum_{j=0}^{J-1} \sum_{k} \tilde{b_{j k}} w_{j k}(t)
$$

Where;

$$
\begin{aligned}
& \tilde{a}_{0 k}=\int y(t) \tilde{\psi}_{0 k}(t) d t \\
& \tilde{\psi}(t)=\sum_{k=0}^{\widetilde{N}} 2 h_{0}(k) \tilde{\psi}(2 t-k) \text { (Analysis dilation equation) } \\
& \tilde{b}_{j k}=\int y(t) \widetilde{w}_{j k}(t) d t \\
& \widetilde{w}(t)=\sum_{k=0}^{\widetilde{N}} 2 h_{1}(k) \tilde{\psi}(2 t-k) \text { (Analysis Wavelet equation) } \\
& \psi(t)=\sum_{k=0}^{N} 2 f_{0}(k) \tilde{\psi}(2 t-k) \text { (Synthesis dilation equation) } \\
& w(t)=\sum_{k=0}^{N} 2 f_{1}(k) \tilde{\psi}(2 t-k) \text { (Synthesis wavelet equation) }
\end{aligned}
$$

Where $h_{0}(k)$ and $h_{1}(k)$ are low pass and high pass analysis filters and $f_{0}(k)$ and $f_{1}(k)$ are low and high

\begin{tabular}{|c|c|c|c|}
\hline \multicolumn{4}{|c|}{ Output Gap } \\
\hline$\underline{\text { Range }}$ & Kalman & Wavelet & SVAR \\
\hline 1993Q1-1994Q4 & $+\mathrm{ve}$ & break even & $+\mathrm{ve}$ \\
\hline 1995Q1-1996Q4 & -ve & -ve & -ve \\
\hline 1997Q1-1998Q4 & -ve & -ve & -ve \\
\hline 1999Q1-2000Q4 & -ve & break even & -ve \\
\hline 2001Q1-2002Q4 & $-v e$ & -ve & -ve \\
\hline 2003Q1-2004Q4 & + ve & $+\mathrm{ve}$ & $+\mathrm{ve}$ \\
\hline 2005Q1-2006Q4 & $+\mathrm{ve}$ & -ve & $+\mathrm{ve}$ \\
\hline 2007Q1-2008Q4 & $+\mathrm{ve}$ & $+\mathrm{ve}$ & $+\mathrm{ve}$ \\
\hline 2009Q1-2010Q4 & -ve & -ve & -ve \\
\hline
\end{tabular}
pass synthesis functions. Using the above representation I estimate a wavelet filter of scale, $J=2$, using a biorthognal representation, consistent with Motohiro, Y., (2008), Figure 2 depicts the output gap for the case of Pakistan estimated using the filter representation stated above.

Table 1a. Descriptive statistics of output gap estimates

\begin{tabular}{lccc}
\hline & Kalman & SVAR & Wavelet \\
\hline Mean & -0.227 & 0.049 & -0.072 \\
Median & -0.455 & 0.071 & -0.397 \\
Maximum & 6.909 & 6.530 & 7.963 \\
Minimum & -7.077 & -5.392 & -8.642 \\
Std. Dev. & 2.902 & 2.686 & 3.712 \\
Kurtosis & 2.792 & 2.399 & 2.883 \\
\hline Correlation & Coefficient between & Estimates of Output Gap \\
\hline \multicolumn{5}{r}{ Kalman } & Kalman & SVAR & Wavelet \\
SVAR & 1 & 0.621 & 0.844 \\
Wavelet & & 1 & 0.589 \\
\end{tabular}

Table 1b. Diagnostics of quarterly output gap estimates 


\begin{tabular}{llll}
\hline 2011Q1-2012Q4 & -ve & $+v e$ & $+v e$ \\
2013Q1-2014Q1 & -ve & $+v e$ & $-v e$ \\
\hline
\end{tabular}

\section{Conclusion and Policy Implications}

One of the most significant aspects of the estimates of output gap from the three different methods is that; although the magnitude of excess capacity (Positive Output Gap) or excess demand (Negative Output Gap) varies with the methods, the general direction of the output gap (both positive and negative) is analogous. This is also evident in the descriptive statistics and correlation coefficients between the estimates. Table 1 identifies periods of excess demand and excess supply for the case of Pakistan (see Table 1b).

Latent variables like the output gap and potential output are notoriously difficult to pinpoint and important still relevant literature suggests the contrary in many studies. Cayen and Van Norden (2004), Gaiduch and Hunt (2000) and Orphanides et al. (2002) identify caveats such as vast differences in estimates, misidentification of models, variation in real time estimates and statistical uncertainty as main obstacles for robust estimation of output gap.

Table 2. Diagnostics of models for forecasting output gap in range FY2014Q2-FY2015Q4

\begin{tabular}{lccc}
\hline Model 1: Based on State-Space Model & & & \\
\hline ARIMA Model & Serial LM Test & $\mathrm{R}^{2}$ & Durbin Watson \\
AR(1,3), I(1), MA $(3,4,6,8)$ & $0.000(1.000)$ & Good & 1.998 \\
\hline Model 2: Based on SVAR Model & & & \\
\hline ARIMA Model & Serial LM Test & $\mathrm{R}^{2}$ & Durbin Watson \\
AR(1, 2, 4), I(1), MA $(5,7,8)$ & $2.359(0.307)$ & Good & 2.209 \\
\hline Model3: Based on Wavelet filtering & & & \\
\hline ARIMA Model & Serial LM Test & $\mathrm{R}^{2}$ & Durbin Watson \\
AR(2,3), I(1), MA(2) & $1.146(0.563)$ & Good & 1.838 \\
\hline
\end{tabular}

Note. Serial LM Test results in brackets are the corresponding probability values.

Corroboration in output gap estimates within the framework of the three methods discussed in this paper is very interesting and insightful for use in policy decisions, this is especially important considering the analysis in this paper is conducted on quarterly frequency, as time series of higher frequency tends to exhibit higher variance.

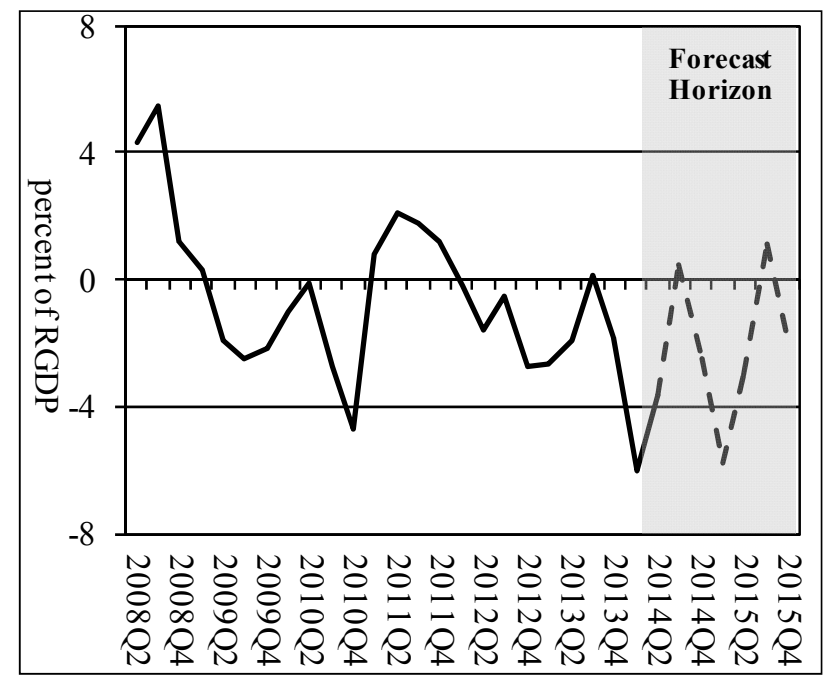

Figure 3. Weighted forecast of output gap using estimates from 3 ARIMA models

Output Gap estimates form important policy blocks in many macroeconomic policies like the Taylor rule. It is therefore understood that direction or trend of Output gap has most significance with respect to forward-looking policy formulation. One important policy query in this regard is that when shall the aggregate demand pick up in 
momentum in the short run in the future. As positive output gap signifies the existence of upbeat Aggregate Demand we can address the policy question by forecasting output gap. In this backdrop I estimated an ARIMA model for forecasting output gap in the short run. Table 2 illustrates diagnostics and results from the ARIMA model, these results depict statistically significant results therefore we can move towards forecasting output gap in the range FY2014Q2-FY2015Q4. Figure 3 depict forecast results from the weighted averages of forecasts from the 3 ARIMA models depicted in Table 2. Concluding; It can be safely stated that aggregate demand is expected to rebound (depicted as positive Output gap) after FY2015Q4.

\section{References}

Adnan, S. H. A. S. B., \& Safdar, U. K. (2008). Estimating output gap for Pakistan economy: Structural and statistical approaches. SBP Working Paper Series, No. 24.

Adnan, H., \& Musleh-ud-Din, E, G. (2013). Monetary policy, informality and business cycle fluctuations in a developing economy: Vulnerable to external shocks. State Bank of Pakistan Working Paper Series, No. 65.

Araujo, C. H. V., Areosa, M. B. M., \& De Carvalho, G. (2004). Estimating potential output and the output gap for Brazil. Banco Central do Brazil.

Baxter, M., \& King, R. G. (1995). Measuring business cycles: Approximate band-pass filters for economic series. NBER Working Paper No.5022.

Benes, J., \& N'Diaye, P. (2004). A multivariate filter for measuring potential output and the NAIRU: Application to the Czech Republic. IMF Working Paper Series, No. 04/45. http://dx.doi.org/10.5089/9781451846508.001

Billmeier, A. (2004a). Ghost busting: Which output gap measure really matters. IMF Working Paper Series, No. $04 / 146$.

Billmeier, A. (2004b). Measuring a roller coaster: Evidence on the finnish output gap. IMF Working Paper Series, No. $4 / 57$.

Bjørnland, H. C., Brubakk, L., \& Jore, A. S. (2006). Forecasting inflation with an uncertain output gap. Norges Bank Working Paper Series, No. 2006/2.

Blanchard, O. J., \& Quah, D. (1989). The dynamic effect of aggregate demand and supply disturbances. American Economic Review, 79(4), 655-673.

Boone, L. (2000). Comparing semi-structural methods to estimate unobserved variables: The HPMV and Kalman filter Approaches. OECD Economic Department Working Paper, No. 240. http://dx.doi.org/10.1787/112875725526

Cayen, J. P., \& Van Norden, S. (2004). The reliability of Canadian output gap estimates. Studies of the Economic Research Centre, Deutsche Bundesbank, Discussion Paper Series 1, No. 29.

Cerra, V., \& Saxena, S. W. (2000). Alternative methods of estimating potential output and the output gap: An application to Sweden. IMF Working Paper Series, No. 00/59.

Changy, O., Lemoine, M., \& Pelgrin, F. (2003). An assessment of multivariate output gap estimates in the Euro area. Eurostat report, 'Short term indicators for the Euro zone,' Luxemburg.

Chantanahom, P., Buranathanang, N., Imudon, W., Rattakul, Y., \& Kiatkomol, P. (2002). Parametric estimation of Thailand's potential output. Bank of Thailand, Discussion Paper.

Clark, P. K. (1987). The cyclical components of us economic activity. Quarterly Journal of Economics, 102(4), 797-814. http://dx.doi.org/10.2307/1884282

Coe, D. T., \& Mcdermott, C. J. (1996). Does the gap model work in Asia. IMF Working Paper Series, No. 69.

Conway, P., \& Hunt, B. (1997). Estimating potential output: A semi-structural approach. Reserve Bank of New Zealand, Working Paper D97/9.

Denis, C., McMorrow, K., \& Roger, W. (2002). Production function approach to calculating potential growth and output gaps-Estimates for the EU member states and the US. Economic Papers, No.176.

Dupasquier, C., Guay, A., \& St-Amant, P. (1997). A survey of alternative methodologies for estimating potential output and the output gap. Journal of Macroeconomics, 21, 577-595. http://dx.doi.org/10.1016/S0164-0704(99)00117-2

Funke, M. (1997). Supply potential and output gaps in west German manufacturing. International Journal of 
Forecasting, 13(2), 211-222. http://dx.doi.org/10.1016/S0169-2070(97)00717-6

Gaiduch, V., \& Hunt, B. (2000). Inflation targeting under potential output uncertainty. IMF Working Paper, No. 128. http://dx.doi.org/10.5089/9781451857573.001

Gibbs, D. (1995). Potential output: Concepts and measurement. Labor Market Bulletin, 1.

Gounder, K., \& Morling, S. (2000). Measures of potential output in Fiji. Reserve Bank of Fiji, Working Paper Series, No. 2000/06.

Grewal, M. S., \& Andrews, A. P. (2001). Kalman filtering theory and practice using MATLAB (2nd ed.). New York, NY: John Wiley \& Sons, Inc.

Harvey, A. C. (1985). Trend and cycles in macroeconmic time series. Journal of Business and Economic Statistics, 3, 216-227.

Harvey, A. C., \& Jaeger, A. (1993). Detrending, stylized facts and the business cycle. Journal of Applied Econometrics, 8(3), 231-247. http://dx.doi.org/10.1002/jae.3950080302

Juillard M., Ondřej, K., Kumhof, M., \& Douglas, L. (2006). Measures of potential output from an estimated DSGE model of the United States. CNB Working Paper Series, No. 11/2006.

Motohiro, Y. (2008). Measuring business cycles: A wavelet Analysis of economic time series. Economic Letters, 100, 208-212. http://dx.doi.org/10.1016/j.econlet.2008.01.008

Orphanides, O., \& Van Norden, S. (2002). The unreliability of output-gap estimates in real time. The Review of Economics and Statistics, 134(4). http://dx.doi.org/10.1162/003465302760556422

Percival, D. B., \& Walden, A. T. (2000). Wavelet methods for time series analysis. Cambridge Series in Statistical and Probabilistic Mathematics. Cambridge: Cambridge University Press. http://dx.doi.org/10.1017/CBO9780511841040

Scott, A. (2000). Stylized facts from output gap measures. Reserve Bank of New Zealand, Discussion Paper Series, No. 7.

Leist, S., \& Neusser, K. (2010). Measuring the natural output level by DSGE models: An empirical investigation for Switzerland. Swiss Society of Economics and Statistics, 146(1), 275-300.

Berger, T., \& Kempa, B. (2011). Bayesian estimation of the output gap for a small open economy: The case of Canada. Economic Letters, 112, 107-112. http://dx.doi.org/10.1016/j.econlet.2011.03.009

Vineet, V. (2004). Estimating output gap for the Indian economy: Comparing results from unobserved-components models and the hodrick-prescott filter. IIMA Working Paper, No. 2004-04-02.

Watson, M. W. (1986). Univariate detrending methods with stochastic trends. Journal of Monetary Economics, 18, 49-75. http://dx.doi.org/10.1016/0304-3932(86)90054-1

Hirose, Y., \& Naganuma, S. (2009). Structural estimation of the output gap: A Bayesian DSGE approach. Economic Inquiry, 48(4), 864-879. http://dx.doi.org/10.1111/j.1465-7295.2009.00228.x

Note

Note 1. The Matlab codes for implementation of Motohiro Y (2008) can be accessed via this link; (https://sites.google.com/site/motohiroyogo/home/research/\#Econometrics)

\section{Appendix A}

Temporal Disaggregation for Obtaining Quarterly Estimated of Real GDP of Pakistan Using Annual Data

Table A1. Elaborating step 2

\begin{tabular}{cc}
\hline Time Period & Sub Period \\
\hline $1978-1980$ & $m=1$ \\
$1981-1983$ & $m=2$ \\
$1984-1986$ & $m=3$ \\
$1987-1989$ & $m=4$ \\
$1990-1992$ & $m=5$ \\
\hline
\end{tabular}




\begin{tabular}{cc}
\hline $1993-1995$ & $m=6$ \\
$1996-1998$ & $m=7$ \\
$1999-2001$ & $m=8$ \\
$2002-2004$ & $m=9$ \\
$2005-2007$ & $m=10$ \\
$2008-2010$ & $m=11$ \\
$2011-2014$ & $m=12$ \\
\hline
\end{tabular}

It must be understood here that the aim of temporal disaggregation exercise is not the extraction of properties and factors impacting the direction of the real output of Pakistan rather it is intended to implement the usage of LSM index as a proxy of Real GDP of Pakistan in order to observe the trend and cyclical components of the time series.

It is stated for reference that in many studies where the data of higher frequency than Annual data is not available, Large Scale Manufacturing Index is commonly used as a proxy, doing so is acceptable theoretically, as in many economies the LSM has a very decent fit to overall Real GDP.

In Pakistan's case the correlation coefficient between Annual RGDP and Annual LSM is 0.99, which is testament to the viability of using Quarterly LSM series for construction of econometrically significant proxy of Real GDP;

We proceed thus;

Step 1: For the Annual series of RGDP and LSM in the range FY1978-FY2013 we calculate;

$$
\frac{R G D P_{t}}{I P I_{t}} \text { for } t=F Y 1978, \ldots, F Y 2013
$$

Step2: We divide the time period in the range FY1978-FY2013 in to equal sub-periods of 3 years;

For every $m=1, \ldots, 12$ we estimate;

$$
\frac{\sum_{t=1}^{3}\left(\frac{R G D P_{m t}}{I P I_{m t}}\right)}{3}=(\text { Multiplication Factor })_{n}
$$

Where $n=m=12$, moving on;

So that when $m=1$

$$
\frac{\sum_{t=l}^{3}\left(\frac{R G D P_{m t}}{I P I_{m t}}\right)}{3}=\frac{\left(\frac{R G D P_{1,1978}}{I P I_{l, 1978}}\right)+\left(\frac{R G D P_{1,1979}}{I P I_{1,1979}}\right)+\left(\frac{R G D P_{l, 1980}}{I P I_{l, 1980}}\right)}{3}=\frac{\left(\frac{1789.96}{14.88}+\frac{1888.91}{1532}+\frac{2027.31}{17.02}\right)}{3}=120.91=(\text { Multiplication Factor })_{1}
$$

Table A2. Elaborating step 3

\begin{tabular}{cc}
\hline Time Period & Multiplication Factor \\
\hline 1978 Q1-1980 Q4 & $n=1$ \\
1981 Q1-1983 Q4 & $n=2$ \\
1984 Q1-1986 Q4 & $n=3$ \\
1987 Q1-1989 Q4 & $n=4$ \\
1990 Q1-1992 Q4 & $n=5$ \\
1993 Q1-1995 Q4 & $n=6$ \\
1996 Q1-1998 Q4 & $n=7$ \\
1999 Q1-2001 Q4 & $n=8$ \\
2002 Q1-2004 Q4 & $n=9$ \\
2005 Q1-2007 Q4 & $n=10$ \\
2008 Q1-2010 Q4 & $n=11$ \\
2011 Q1-2014 Q4 & $n=12$ \\
\hline
\end{tabular}

After calculating the (Multiplication Factor) for $n=m=12$, we proceed as;

Step 3: To arrive at an estimate of Real GDP on Quarterly basis for every quarter between FY1978Q1FY2014Q1, we estimate;

$$
R G D P_{Q_{i}}=\left\{(\text { Multiplication Factor })_{n}\right\} \times I P I_{Q_{i}}
$$


Where (Multiplication Factor) ${ }_{n}$ shall evolve in the above equation as under (see Table A2). Whereby we shall now get RGDP for each quarter between FY1978Q1-FY2014Q1.

\section{Copyrights}

Copyright for this article is retained by the author(s), with first publication rights granted to the journal.

This is an open-access article distributed under the terms and conditions of the Creative Commons Attribution license (http://creativecommons.org/licenses/by/3.0/). 